\title{
Ozone Therapy In Dentistry
}

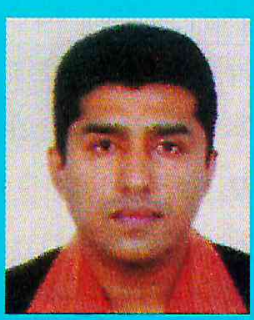

Dr. Sathyajith Naik N. Professor

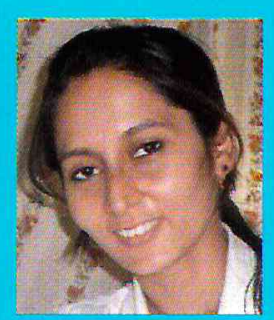

Dr. Sabha Sheik Post Graduate

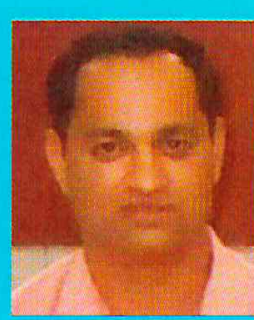

Dr. Shashibhushan Professor

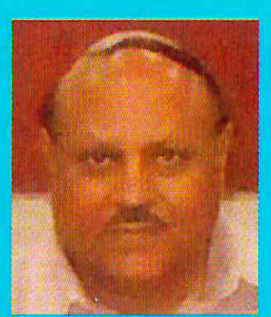

Dr. V. V. Subba Reddy Principal \& Head

\section{Department Of Pedodontics and Preventive Dentistry}

\section{Introduction :}

The use of ozone in dentistry is gaining its place in every day's dental practice and is used in almost all dental applications. The undisputed disinfection power of ozone over other antiseptics makes the use of ozone in dentistry a very good alternative and/or an additional disinfectant to standard antiseptics. ${ }^{(1)}$ Due to safety concerns, $\mathrm{O} 3$ gas was not recommended for intra-oral use. Only dissolved ozone in water and ozonated oils were and are still commonly used in different fields of dentistry. With the development of a footpedal-activated dental handpiece with a suction feature, $\mathrm{O} 3$ gas can now be used safely in situations where diffusion is an important factor, i.e. dental hard tissues.

\section{What is ozone?}

The term OZONE is derived from the Greek word OZEIN which means odor. ${ }^{(2)}$ Ozone is an allotropic form of oxygen with a three atom molecule. Ozone is one of the most important gases present in the stratosphere surrounding the earth.

Ozone is also created in areas where there is intense physical stress on water like waterfalls and ocean waves crashing into the rocks. ${ }^{(3)}$

Ozone protects living organisms by surrounding the earth at altitudes of 50,000 to 100,00 feets. The ozone layer absorbs the harmful ultra-violet rays present in the light spectrum from the sum and thus allowing for survival of plants, animals and human beings. ${ }^{(4)}$ Ground level ozone is an air pollutant with harmful effects on respiratory the system. ${ }^{(5)}$

Ozone therapy is one of the modern non-medication methods of treatment. It is being used for more than 100 years. Medical reports on successful application of ozone in therapy of different diseases and studies of its effects caused a rapid growing interest in it. Some other factors were responsible for its wide spreading, such as simplicity of performance, good tolerance by patients, absence of sideeffects or adverse reactions and high medical-social and economic efficiency. ${ }^{(5)}$

\section{Characteristics of ozone :}

1. Ozone is an energized form of oxygen with the chemical formula $\mathrm{O}_{3}$.

2. It is a strong oxidant.

3. Ozone is thermodynamically highly unstable compound that, depending on system conditions like temperature and pressure, decomposes to pure oxygen within a short life.

4. Molecular weight is $47.98 \mathrm{~g} / \mathrm{mol}$. (2)

5. Pale blue gas, at $-112^{\circ} \mathrm{c}$ condenses to form a dark blue liquid.

6. It is slightly soluble in water and much more soluble in inert non polar solvents such as carbon tetrachloride and fluorocarbons where it forms 'blue' solution.

7. $0.01 \mathrm{ppm}$ of ozone in air can be detected as it has a very specific sharp odor, somewhat resembling chlorine bleach.

8. Exposure to 0.1 to $1 \mathrm{ppm}$ produces headache, burning eyes and irritation to the respiratory passages.

\section{Composition of medical grade ozone:}

Medical grade ozone is a mixture of pure oxygen and pure ozone in the ratio of $0.05 \%$ to $5 \%$ of 33 and $95 \%$ to $999.95 \%$ of O2. Due to the instability of ozone molecule it must be prepared immediately before use and cannot be stored over 
long periods of time. ${ }^{(11)}$

\section{Ozone generating system :}

There are three different systems for generating ozone gas: (11, 12)

- Ultraviolet System : produces low concentrations of ozone, used in esthetics, saunas, and for air purification.

- Cold Plasma System : used in air and water purification.

- Corona Discharge System: produces high concentrations of ozone. It is the most common system used in the medical/ dental field. It is easy to handle and it has a controlled ozone production rate.

Routes of ozone Administration in Dentistry :

Forms of application in dentistry are: ${ }^{(13,14)}$

As an infusion into infected jaw bones (cavities).

As an Infusion into the temporomandibular joint for the treatment of pain and inflammation.

As an irrigant during root canal therapy to disinfect the involved tooth.

Adjunctive therapy with the use of ozonated olive oil for periodontal diseases.

\section{Clinical Procedures : $:^{(1)}$}

\section{Operative Dentistry}

After a comprehensive diagnosis and caries risks assessment, the clinician should be able to classify the caries lesions according to the severity index upon which he/she would be able to make a clinical judgment on how to proceed with treatment.

\subsection{Primary Pits \& Fissures Caries Lesions}

The following table is an aid on how to perform ozone therapy depending on clinical cases. Remember that the availability of minimally invasive diagnostic and operative equipment is of great value in conjunction with the use of ozone.

\section{Abbreviations:}

CSI: Caries Severity Index

DV: Diagnodent Value

AA:AirAbrasion

\section{O3: Ozone}

EDJ: Enamel Dentin Junction

GIC: Glass Ionomer Cement

Ozone concentration: $3.5-5 ? \mathrm{~g} / \mathrm{ml}$

Flow Rate: 0.5 - $1 \mathrm{~L} / \mathrm{min}$

It is advisable to apply a remineralizing agent after the ozone application. Always emphasize on home oral hygiene and balanced diet.

\subsection{Proximal Caries Lesions}

Proximal caries lesions are readily diagnosed with BiteWing X-Rays unlike occlusal ones. Depending on the depth and speed onset of the lesions, a decision is made on whether to open and access the lesion or to use a non-invasive treatment.

As a general rule, in non-cavitated low speed onset lesions confined in enamel or at the EDJ, a non-invasive protocol should be used first. If the lesion extends in dentin, the final judgment should be based on the caries risks assessment of the patient. In cavitated lesions, restoration is a must.

Follow the same guidelines as described in the pits and fissures protocol.

\subsection{Cervical Root(s) Caries Lesions}

Follow the same guidelines as described in the pits and fissures protocol.

\subsection{Hyper-Sensitive Teeth}

Non-carious hypersensitivity is due to many contributing factors among which are erosion, abfraction, bite pressure, recessed gum, etc.

Quick and prompt relief from root sensitivity has been documented after ozone spray for 60 seconds followed by mineral wash onto the exposed dentine in a repetitive manner. This desensitization of dentine lasts for longer period of time. Smear layer present over the expose root surface prevents the penetration of ionic Calcium and Fluorine deep into the dentinal tubules. Ozone removes this smear layer, opens up the dentinal tubules, broadens their diameter and then Calcium and Fluoride ions flow into the tubules easily, deeply and effectively to plug the dentinal tubules, preventing the fluid exchange through these tubules. Thus, ozone can effectively terminate the root sensitivity problem within seconds and also results last longer than those by conventional methods. ${ }^{(9)}$

\subsection{Cracked Tooth Syndrome}




\begin{tabular}{|c|c|c|c|c|}
\hline & DV & ClinicalAspect & Description Diagnosis & Treatment/Ozone \\
\hline & $<10$ & Probably Sound & $\begin{array}{l}\text { Prophylaxis and Preventive } \\
\text { measures might be needed }\end{array}$ & $\begin{array}{l}10 \mathrm{Sec} \mathrm{O} 3 \text { / Seal Fissures if indicated } \\
\text { with GIC }\end{array}$ \\
\hline & $10-19$ & White Spot & $\begin{array}{l}\text { Not Visible on X-Rays; } \\
\text { Limited to Enamel }\end{array}$ & $\mathrm{AA} / \mathrm{Etch} / 40 \mathrm{Sec} \mathrm{O} 3$ / Seal Fissures \\
\hline & $20-24$ & Caries atEDJ & $\begin{array}{l}\text { Stained Pits and Fissures; } \\
\text { not visible on X-Rays }\end{array}$ & $\mathrm{AA} / \mathrm{Etch} / 40 \mathrm{Sec} \mathrm{O} 3$ / Seal-Restore \\
\hline & $25-29$ & $\begin{array}{l}\text { Caries at } 1-2 \mathrm{~mm} \\
\text { in Dentin }\end{array}$ & $\begin{array}{l}\text { Infected Dentin; probably } \\
\text { not visible on X-Rays }\end{array}$ & $\begin{array}{l}\text { AA/Slow speed rotary. Remove only } \\
\text { infected very soft dentin to reach } \\
\text { leathery dentin. Etch/60 Sec O3/ } \\
\text { GIC/Co-Cure }\end{array}$ \\
\hline & $>30$ & $\begin{array}{l}\text { Caries at } 3 \mathrm{~mm} \\
+ \text { in Dentin }\end{array}$ & $\begin{array}{l}\text { Infected Stained Dentin; } \\
\text { probably visible on X-Rays }\end{array}$ & $\begin{array}{l}\text { AA/Slow speed rotary, remove only } \\
\text { infected very soft dentin to } \\
\text { reach leathery dentin. Etch/60-120 Sec } \\
\text { O3/GIC/Co-Cure }\end{array}$ \\
\hline 6 & $>99$ & $\begin{array}{l}\text { Very deep caries; may } \\
\text { be pulp involvement }\end{array}$ & $\begin{array}{l}\text { Assess Pulp Vitality Decision } \\
\text { Making }\end{array}$ & $\begin{array}{l}\text { Remove all soft infected dentin; stop at } \\
1-2 \text { mm from pulp; Etch/120 } \\
\text { Sec O3/ GIC Fuji VII. Re-assess at } 4 \\
\text { month with X-Rays; remove } \\
\text { GIC and look for re-mineralization of } \\
\text { the floor of the cavity. If good } \\
\text { results, put final restoration. }\end{array}$ \\
\hline
\end{tabular}

According to the clinical situation and symptoms, a conservative attempt can be used with ozone application. After revealing the crack and evaluation of the case, apply ozone gas for $60-120 \mathrm{sec}$ and restore with a long term temporary filling, i.e.: GIC. Put the tooth slightly off occlusion.

\section{Reassess periodically.}

\section{Root Canal Therapy - Peri-Apical Lesions}

Ozone is highly indicated in root canal therapy due to its strong disinfection property and absence of cytotoxicity as well as other negative side effects at the recommended used concentration and form (gas or dissolved in water). Ozonized oils can also be used as a temporary canal(s) dressing in infected necrotic cases. In peri-apical lesions, ozone gas infiltration contributes in the non-surgical management of these lesions.

\subsection{Vital Root Canal Therapy}

After final shaping and cleaning of the canal(s), adapt a 25$27 \mathrm{G}$ needle on the delivering central tip of the handpiece, making sure not to obliterate the free gas circulation inside the round tapered housing. Cut a piece of PVC or silicone tube according to the clinical situation in order to seal the access cavity with the needle inside the canal. The needle should not block the intra-canal gas circulation towards the canal orifice.

Fill the canal with saline or distilled water and apply ozone for 2-3 minutes per canal at $5 \mu \mathrm{g} / \mathrm{ml}, 0.5-1 \mathrm{~L} / \mathrm{min}$ flow rate.

During the canal shaping and irrigation, ozonated water can be used as a disinfectant and irrigant.

\subsection{Necrotic Root Canal Therapy}

In some situations, there is a need to disinfect the root canal system with a temporary dressing until the symptoms are relieved and the canal(s) are ready to be filled. Follow the same protocol as above and use ozonized olive oils as a temporary disinfection dressing. Fill a 1cc disposable syringe with the oil and adapt a $25 \mathrm{G}$ needle. Insert the needle as deep as possible inside the canal and inject slowly while retrieving the needle slowly out of the canal. You can also use a Lentulo to fill the canal with the ozonized oil.

\subsection{Peri-Apical Lesions}

Local anesthesia is recommended in this procedure. In 
maxillary peri-apical lesions, ozone infiltration is performed the same way you give a local anesthetic injection on the buccal side. Depending on the size and severity of the lesion, the concentration varies between 5 and $10 \mu \mathrm{g} / \mathrm{ml}$ at a volume of $1-3 \mathrm{cc}$. Inject the gas very slowly as close as possible to the site of the lesion. Repeat the infiltration once a week until resolution of the symptoms.

In mandibular peri-apical lesions, the use of an intraosseous needle to deliver the ozone gas right into the bone is indicated. Use your preferred technique to perforate the cortical bone, making sure to stay away of the alveolar inferior canal and mental nerve. The access point is usually 2-3 mm under the free gingival level where the cortical bone is easily perforated. Inject very slowly as described above.

\section{Periodontal Therapy}

Gingival and Periodontal diseases represent a major concern both in dentistry and medicine. The majority of the contributing factors and causes in the etiology of these diseases are reduced or treated with ozone in all its application forms (gas, water, oil).

According to the clinical case, different applications modalities are available using ozone gas, irrigation with ozonated water and in-office use of ozonized oil as well as home use.

\subsection{Gas application via a customized thermoformed dental appliance}

Prepare a suckdown thermoformed hard or medium-soft dental appliance extending 2-3 $\mathrm{mm}$ beyond the affected gingival area, leaving a free space for gas circulation. Attach 2 ports for the gas inlet and outlet respectively at the distal and mesial of the treatment area. Reline the edges of the appliance with light or medium body silicone. Light-cured dam can also be applied as an extra safety precaution to completely seal the borders. Attach the ports to the generator and the suction pump. This procedure will treat both hard and soft tissues of the affected area. You can always use the PVC or silicone cap and treat individually all the indicated areas in difficult situations where such an appliance is hard to use or uncomfortable to the patient.

\subsection{Irrigation with Ozonated Water}

Prepare the ozonated water using Acquazone and generously irrigate the affected area during and after scaling, root surface planning, and non-surgical pocket curettage.

\subsection{In-office and Home Use of Ozonized Olive Oil}

After in-office treatment with ozone gas or ozonated water, fill the pockets with ozonized olive oil using a blunt $25 \mathrm{G}$ needle or any other appropriate tip. Give the patient for home use some of the oils and instruct him/her on proper application. Repeat the in-office ozonized oil application once a week.

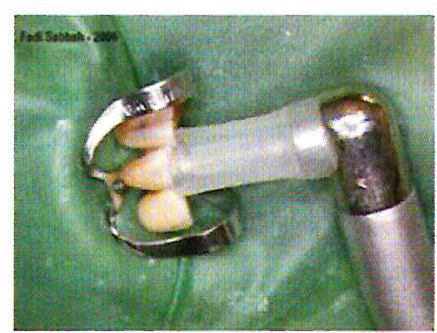

An adapted silicone cap and $25 G$ needle for ozone gas canal disinfection

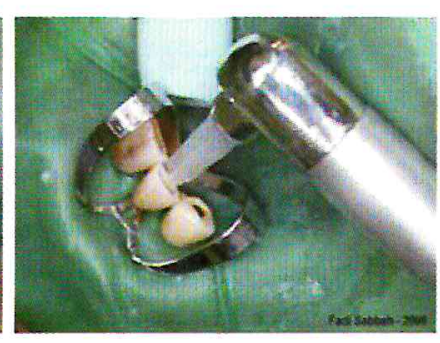

In case a silicone cap is unpractical put the suction tip close to the canal orifice

\section{Post-Extractions-Surgery}

In dental/oral surgery, the use of ozone is indicated during the surgical intervention as well as post-surgery as a topical disinfectant and healing agent. In these procedures, the use of ozone gas is not convenient due to the inability to properly seal the treated area. Ozonated water and oils are therefore the forms of application.

\subsection{Post-Extraction}

After final debridement of the socket, irrigate with copious amounts of ozonated water and then use gauze imbibed with ozonated water to compress the extraction site. Before retiring the patient, fill the socket with ozonized oil and cover it with gauze.

\subsection{Post-Extraction Alveolitis}

After thorough assessment, remove the necrotic plug and debris from the extraction site, irrigate with large amounts of ozonated water then fill the alveoli with ozonized oil. Antibiotic coverage may be indicated. Instruct the patient to apply ozonized oil 3-4 times a day until total healing.

\subsection{Surgical Procedures}

Ozonated water can be used as an irrigant during the surgical procedure and/or as a final surgical site lavage. Cover the sutures with a thin layer of ozonized oil and instruct the patient to apply the oil 3-4 times a day.

\subsection{Peri-Implantitis}

Peri-implantitis is very bothering to both the dentist and the patient. After thorough assessment and if a decision is taken to salvage the case, different modes of therapy are used in 
order to save the implant from total loss.

Ozone can play an important role and be used as gas or in aqueous form. Cut an appropriate length of PVC or silicone cap and cover fully the abutment. In case the crown is still present, it is advisable to remove it for proper sealing of the abutment and the gingival borders around the implant. Ozone gas infiltrations are also helpful in this situation. Ozonated water can be used as an irrigant during debridement and curettage. Advise the patient to apply ozonized oil on the treated area 3-4 times/day.

\section{Crowns \& Bridges - Veneers - Removable Dentures}

\subsection{Crowns \& Bridges - Veneers}

The black stain that we see under the temporaries, mainly in the shrink-wrap veneers temporization technique is due to the presence of bacteria. The use of ozone gas to both disintegrate the smear layer and disinfect the prepared teeth is highly recommended. The use of air abrasion before ozone is an advantage to completely remove microscopic debris and smear layer from the surface of the abutments and to leave a clean dentin for ozone disinfection.

The recent research and published articles show that ozone use do not affect the adhesive bonding procedures. ${ }^{(1)}$

Use ozone gas to disinfect the prosthesis. Ozonated water can also be used.

\subsection{Removable Dentures}

A common occurrence found in full dentures wearers is denture stomatitis, mainly due to Candida albicans. Whether white patches or erythematous forms, ozone use, mainly ozonated water and oil, is highly efficient in this situation and also helps in the cleaning and disinfection of the dentures acrylic material.

Prepare ozonated water using Acquazone and soak the denture(s) after thorough cleaning and removal of hard deposits. Imbibe a $5 \times 5 \mathrm{~cm}$ gauze with the prepared ozonated water and apply on the affected areas. Refresh the gauze with ozonated water frequently or replace with a new one.

Remove excess water from the dentures and apply few drops of ozonized oil on the inside of the denture(s) and seat firmly.

\section{Soft Tissue Lesions}

All kinds of infectious, inflammatory, traumatic, burns, wounds, soft tissue lesions respond very well to topical ozone treatment. As mentioned earlier, the beneficial biological effects of ozone and its disinfectant / healing properties make the use of ozone highly recommended in these situations.

\subsection{Ozone Gas Application}

Seal the affected area with a PVC or silicone cap and apply ozone gas for 1-2 minutes. Repeat if necessary.

In case of cyst fistula, insert a plastic needle slowly in the passage of the fistula and inject 1-2 cc of ozone gas. Anesthesia might be indicated in this procedure.

\subsection{Ozonated Water Application}

In situations of large traumatic wounds, burns and cuts, the combined use of ozone gas and ozonated water are indicated. For ozone gas, follow the above-mentioned protocol. Prepare the ozonated water using Acquazone ozonated water column and irrigate for 10 minutes the affected area. In case of supra-infected lesions, use a strong preparation of ozonated water. During the healing phase, a mild solution is more appropriate.

\subsection{Ozonized Olive Oil Application}

In many instances, the soft tissue lesions we frequently see can be managed with only daily home application of ozonized olive oil. These oils have a greater advantage over commonly used antiseptics and ointments due to their wide range of activities during all phases of the healing process.

\section{OtherApplications}
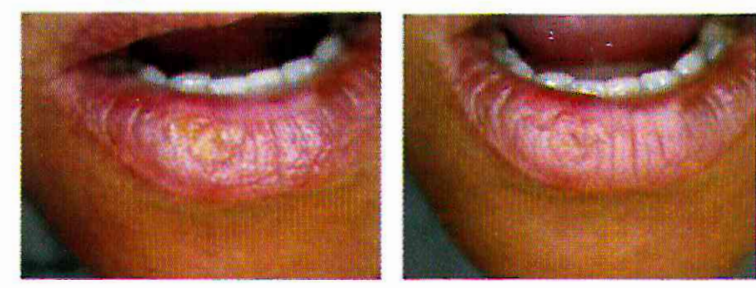

Herpetic lesion treated with 2 minutes application of ozone gas. The "After' picture taken 40 minutes post-ozone application

\subsection{Whitening with Ozone}

In root canal treated teeth, after removing the root canal filler material from the pulp chamber, the canal is sealed tight at the level of cementoeonamel junction. Then, the chamber is cleansed with sodium peroxide solution to remove any debris, cement particles and the smear layer, leaving the dentinal tubules opened-up. Now, a bleaching paste or a cotton pellet moistened in bleaching solution is packed in the chamber and the orifice is sealed with the Glass-ionomer cement. After placing the bleaching agent in to the inner of the tooth, the crown is irradiated with ozone 
for minimum of 3-4 minutes. This ozone treatment bleaches the tooth within minutes and gives the patient a happy and healthier-looking smile. ${ }^{(9)}$

\subsection{Dental Unit Water Lines Disinfection - Office Tap Water Disinfection}

Dental unit water lines are known to carry hard to remove biofilms inside them. Besides the bad odors coming out of these dirty water lines, the microbial biofilm may represent a source of infection to patients, especially who have a deficient immune system or the elderly. Many studies showed almost complete disintegration and elimination of dental unit water lines biofilms with ozonated water.

\subsection{Instruments Cold Disinfection}

Ozonated water can also be used as a cold disinfection solution for medical and dental instruments, as well as for cabinets countertop disinfection. Ozonated water can also be used as hands wash disinfectant solution, fiber optic tips, contact lenses, surgical loupes lenses, etc.

\subsection{TMJ Peri-Articular Ozone Gas Injection - Trigger Points}

The bio stimulation and anti-inflammatory effects of ozone help in the mranagement of articulation inflammatory diseases and muscular trigger points. Chronic oxidative stress and elevated levels of pro-inflammatory cytokines are commonly found in these skeletal chronic inflammations where ozone gas infiltration can contribute in stimulating the anti-oxidant defense mechanism and in balancing the immune response by modulating the production of cytokines.

\section{Contraindication $^{(5,11,12)}$}

- acute and chronic tendency to bleedings;

- thrombocytopenia;

- hyperthyroidism;

- cramps in the anamnesis;

- individual intolerance to ozone;

- blood coagulation disorder;

Ozone should be used most carefully in case of decompensated conditions:

- in decompensated heart insufficiency;

- in severe acute toxication (incl. alcohol);

- in hypoglycemic conditions;

- in extremely sympathicotonic and parasympathicotonic reactions.

After myocardial infarction ozone therapy can be used not earlier than after 6 months, in patients with hemorrhagie insult in the anamnesis ozone therapy is not recommended for use.

\section{The Benefits of Ozone Dental Treatment:}

\section{Simple treatment}

- Completely pain free procedure

- Eliminates damage and unnecessary tooth reduction since there is no drilling.

- Eliminates the use of anesthesia

- Kills $99 \%$ of bacteria in cavities

- Excellent for nervous or anxious patients

- Produce huge financial gains for;

$\checkmark$ the state in terms of reduced funded dental care, lost work time;

$\checkmark$ for the patient, in terms of reduced cost and time off work;

$\checkmark$ for the dental practioner, in terms of increased income, reduced time, reduced failure, and enhanced 'professionalism'.

\section{REFERENCES :}

1. Dr Fadi Sabbah. Ozone Therapy in the Dentistry. www.medozons.com

2. Dr P L Ravishankar, Dr C H Srikrishna, Dr B V V Srinivas. Role of Ozone in Dentistry. An over view. Indian Dentist Research and Review July 2010; $42-47$

3. Alan Holland. Ozone in Endodontics: Endo practice Feb 2010; 6-10

4. Mollica Phillip, Harris Robert : Integrating oxygen/ozone therapy into your practice. [online]. (cited 2010 January 13) Available from: URL:http://www.Toxin free smile.com/images/ Integrating oxygen/ozone therapy into your practice/Pdf

5. Seidler V, Linetsky L, Hubakova H, Stankova H, Smucler R, Mazanek J. Prague Medical Report vol 109(1) 5-13,2008.

6. Sunnan G V: Ozone in Medicine-overview and future directions. JAdv Med 1988.1(3):159-174

7. Stubinger S, Sader R. The use of ozone in dentistry and maxillofacial surgery- A review. Quintessence Int 2006;37:353-359

8. Ozone Dental therapy. (online) Available from. URL:http://www.safedentistry.co.uk/ozone-dental therapy.html

9. Ozone therapy in Dental Practice : A New Face [on 1 ine ] Available from : URL:http://www.standard-insurance/blog/ozonetherapy-in-dental-practice-new-face.htm. 